\title{
Direct Medical Cost of Treatment of uncomplicated malaria after the Adoption of artemisinin-Based Combination Therapy in Nigeria
}

\author{
Ebere Emilia Ayogu, Adaobi Uchenna Mosanya*, Jude Chidiebere Onuh, Maxwell Ogochukwu Adibe, Chukwuemeka Michael \\ Ubaka, Chinwe Victoria Ukwe \\ Department of Clinical Pharmacy and Pharmacy Management, Faculty of Pharmaceutical Sciences, University of Nigeria, Nsukka, Nigeria.
}

\begin{tabular}{l}
\hline ARTICLE INFO \\
\hline Received on: $19 / 01 / 2021$ \\
Accepted on: 30/03/2021 \\
Available online: 05/09/2021 \\
\hline Key words: \\
Artemisinins, direct costs, \\
humans, malaria, Nigeria.
\end{tabular}

\section{INTRODUCTION}

As a low- and middle-income country, Nigeria faces the health burden caused by communicable diseases, such as malaria (Babamale and Ugbomoiko, 2016), in addition to that produced by noncommunicable diseases, such as cardiovascular diseases (Maiyaki and Garbati, 2014). Although there has been a significant decline in the global morbidity and mortality caused by malaria between 2010 and 2018 from 251 million to 228 million, the African region bore the highest malaria burden with 213 million cases only in 2018. Moreover, 19 African countries from the sub-Saharan region and India bore $85 \%$ of the global malaria burden. In addition, $50 \%$ of this is shared by only six countries of which Nigeria is inclusive (World Health Organization, 2019). It is endemic in most parts of Nigeria, while the rural and suburban

\section{"Corresponding Author}

Adaobi Uchenna Mosanya, Department of Clinical Pharmacy and Pharmacy Management, Faculty of Pharmaceutical Sciences, University of Nigeria, Nsukka, Nigeria.E-mail: adaobi.mosanya@ @nn.edu.ng areas disproportionately bear the highest burden (Ezenduka et al., 2017). In fact, different locations are associated with varied malaria risks for both epidemiological and socioeconomic reasons (Babamale and Ugbomoiko, 2016).

Malaria for a long time has been considered a disease of poverty as well as one that aggravates poverty because it is predominantly transmitted in the regions of low to middle income including Nigeria (Worrall et al., 2005). It affects the health and wealth of nations (Okorosobo et al., 2011). Both past and recent studies have demonstrated this link through its effect on GDP per capita of the investigated countries (Ahuru and Omon, 2018; Okorosobo et al., 2011; Tefera et al., 2020). On the individual level, malaria is associated with an economic burden and catastrophic costs due to expenses incurred from medical treatment, income losses from absenteeism from work, and unexpected death. Poverty is a risk factor for malaria because people with low income have a lower health-seeking attitude for effective, prompt medical care and are less likely to have access to the means of disease prevention (Xia et al., 2016).

The Nigerian Federal Ministry of Health in February 2005 in response to the WHO guidelines released a national 
antimalaria treatment policy for the purposes of strengthening and scaling up the effective malaria case management (Federal Ministry of Health, 2005). However, the constraints of artemisinin combination therapies (ACTs) are access, delivery, and cost. Economic evaluation of healthcare services is an important task because health resources are limited in most low- and middleincome countries like Nigeria. Moreover, costs incurred by the consumer, provider, and society are different. This invariably means that they should be investigated separately (Dalaba et al., 2014).

In Nigeria, there are various sources of financing healthcare such as nongovernmental organizations, taxation, direct payment [out-of-pocket (OOP)]), funds from external donors, and health insurances (social and community). Unfortunately, OOPs are projected to constitute the majority, accounting for approximately $77 \%$ of the current healthcare expenditure and \$64 per capita in 2018 (World Health Organization, 2014). It is paramount to state that the average income in Nigeria is $\$ 1,766$ yearly, while the majority of skilled labor workers go home with about $\$ 440$ per annum (Udezi et al., 2010). Meanwhile, more than $58 \%$ of Nigerians earn below $\$ 1.25$ per day (The World Bank, 2015).

Notably, past and recent studies have shown the efficacy of ACTs for malaria treatment and patient outcomes (Falade et al., 2008; Okoli et al., 2010). Others were on the economic burden of malaria treatment from the willingness-to-pay (WTP) approach (Jimoh et al., 2007), health facility cost of malaria treatment (Ezenduka et al., 2017), and direct and indirect cost of malaria treatment from the perspective of the patient (Obieche and Odili, 2016). However, there is none based on the direct medical cost of treatment of uncomplicated malaria from patients' perspectives since the adoption of ACTs. Therefore, this study aimed to evaluate the direct medical cost which includes the cost of the drug, laboratory investigation, and hospitalization incurred by patients after the adoption of ACTs as first-line treatment for malaria disease.

\section{METHODS}

\section{Study design and sSetting}

The study was a retrospective survey that employed the use of a data collection form to collect and evaluate the folders of patients with uncomplicated malaria at the District Hospital and Bishop Shanahan Hospital Nsukka, Enugu State. The population of Enugu State is 3.6 million with a total land area of 7,618 sq. $\mathrm{km}$ (National Bureau of Statistics, 2006). The state has 17 local government areas and Nsukka Local Government is one of them. This lies within the Guinea-Savanna forest belt with an annual rainfall of $1,520-2,030 \mathrm{~mm}$ and temperature ranges between $22.4^{\circ} \mathrm{C}$ and $30.8^{\circ} \mathrm{C}$. Malaria is endemic in this area and it is transmitted all year round having a peak in the rainy season from the months of April to October. Bishop Shanahan Hospital is a private missionary hospital in Nsukka. It is situated in the middle of the town. Bishop Shanahan Hospital is one of the largest secondary care hospitals in Nsukka and serves as a referral center from other smaller hospitals within the region. District Hospital Nsukka is a government-owned secondary hospital built for the healthcare of the inhabitants of the district. It is fully funded and managed by the government and the cost of treatment is subsidized.

\section{Sample population and sample size}

Ethical approval for the study was obtained from the Ethics Review Board, University of Nigeria Teaching Hospital, Ituku-Ozalla Enugu State, with the number NHREC/05/01/2008BFWA00002458-IRB00002323. Approval was also obtained from the management of Bishop Shanahan Hospital and Nsukka District Hospital.

Patient identity and clinical details were kept confidential. The sample population comprised all the patients' folders in the hospital archives from 2014 to 2018, and the sample size comprised all the uncomplicated malaria patients' folders within the same period. All the patients who were diagnosed with severe malaria and other diseases, as well as all cases with incomplete data, were excluded.

\section{Data collection}

Data were collected from the two hospitals in July 2018. A data collection form was used to collect the information. The form was divided into two sections. Section one is the socio-demographic and clinical details section made up of gender, marital status, occupation, presence of parasite, and indication of hemoglobin level, while section two contains the direct medical services offered consisting of drugs prescribed, number of hospital visits per year, number of hospitalizations, and length of stay of admitted patients in the hospital. A standard drug price list by the National Health Insurance Scheme (second edition) was used for the costing of the medications used for managing malaria and malaria-related symptoms. The costs of drugs used to treat diseases not related to malaria were excluded. The data collected included the cost borne by the patient and not the cost incurred by the government or the facility. We did not include indirect costs which consist of the patient's income lost due to lost workdays and income lost by the companion/caregiver due to absenteeism from work.

\section{Data analysis}

The data were entered into the Statistical Package for the Social Sciences() V. 22 software. Descriptive statistics were conducted on the selected patients' variables: gender, marital status, occupation, and study site. The direct costs included payment for laboratory examination and antimalarial drugs and consultation fees. The malaria economic costs were computed using the direct medical costs in Nigerian Naira.

\section{RESULTS}

\section{Socio-demographic Information of the Patients}

A total number of 2,420 folders were analyzed. There were more females $(60.7 \%)$ than males, and more than half of the patients were married $(67.8 \%)$. Also, a greater proportion of the patients $(47.1 \%)$ were self-employed. The patient population in Bishop Shanahan Hospital was more (68\%) than in the District Hospital (32\%). The frequency and percentage of other sociodemographic characteristics are presented in Table 1.

\section{Clinical characteristics of patients}

About $84.9 \%$ of the patients were outpatients, while $98.8 \%$ of them visited the hospital once. Also, $52.3 \%$ of the patients were hospitalized for 2 days, while $81.3 \%$ of the patients were not sent for a malaria parasite test before diagnosis and treatment with 
Table 1. Socio-demographic information of the patients.

\begin{tabular}{|c|c|c|}
\hline Variables & Frequency & Percentage \\
\hline \multicolumn{3}{|l|}{ Gender } \\
\hline Male & 951 & 39.3 \\
\hline Female & 1,469 & 60.7 \\
\hline \multicolumn{3}{|l|}{ Marital status } \\
\hline Single & 628 & 26.0 \\
\hline Married & 1,641 & 67.8 \\
\hline Divorced/separated & 151 & 6.2 \\
\hline \multicolumn{3}{|l|}{ Occupation } \\
\hline Student & 345 & 14.3 \\
\hline Self-employed & 1,140 & 47.1 \\
\hline Civil servant & 491 & 20.3 \\
\hline Private company & 333 & 13.8 \\
\hline Unemployed & 111 & 4.6 \\
\hline \multicolumn{3}{|l|}{ Study Site } \\
\hline District hHospital & 775 & 32.0 \\
\hline Bishop shanahan & 1,645 & 68.0 \\
\hline \multicolumn{3}{|l|}{ Year of treatment } \\
\hline 2014 & 336 & 13.9 \\
\hline 2015 & 509 & 21.3 \\
\hline 2016 & 612 & 25.3 \\
\hline 2017 & 754 & 31.2 \\
\hline 2018 & 209 & 8.6 \\
\hline Total & 2,420 & 100 \\
\hline
\end{tabular}

antimalarial drugs. Moreover, the hemoglobin level of about $99 \%$ of the patients was not checked. Table 2 presents the details about the clinical characteristics of the patients.

\section{Antimalarial drugs used in the treatment of uncomplicated malaria}

From the total number of patients, $64.6 \%$ used artemether-lumefantrine tablets, while $13.3 \%$ used artemether (intramuscular injection) and artemether--lumefantrine tablets. Other antimalarial drugs utilized are shown in Table 3.

\section{Total Cost of Treatment of Uncomplicated malaria}

The mean cost of antimalarial drugs used was $748.87 \pm$ 336.75 NGN and the cost of other drugs used was $267.23 \pm 154.85$ NGN. The total mean direct cost of treatment of uncomplicated malaria treatment was $2,234.07 \pm 1,307.59 \mathrm{NGN}$. The details are described in Table 4.

The correlation between the total Cost of Treatment and the Number of Days Hospitalized

None of the socio-demographic variables was continuous, so we could not run any correlation analysis between them and the total medical cost. However, there were two clinical characteristics that were continuous, namely, the number of visits and the number of days hospitalized. The number of days hospitalized had a significant positive correlation with the total cost of treatment $(r=0.356, p<0.001)$.
Table 2. Clinical characteristics of the patients.

\begin{tabular}{|c|c|c|}
\hline Variables & Frequency & Percentage \\
\hline \multicolumn{3}{|l|}{ Patient status } \\
\hline Outpatient & 2,055 & 84.9 \\
\hline Inpatient & 365 & 15.1 \\
\hline \multicolumn{3}{|l|}{ No of visits } \\
\hline 1 & 2,392 & 98.8 \\
\hline 2 & 26 & 1.1 \\
\hline 3 & 2 & 0.1 \\
\hline \multicolumn{3}{|c|}{ Days hospitalized } \\
\hline 1 & 25 & 6.8 \\
\hline 2 & 191 & 52.3 \\
\hline 3 & 144 & 39.5 \\
\hline 4 & 5 & 1.4 \\
\hline \multicolumn{3}{|c|}{ Hemoglobin level } \\
\hline No & 2,389 & 98.7 \\
\hline Yes & 31 & 1.3 \\
\hline Total & 2,420 & 100.0 \\
\hline \multicolumn{3}{|c|}{ Malaria parasite } \\
\hline No & 1,968 & 81.3 \\
\hline Yes & 452 & 18.7 \\
\hline Total & 2,420 & 100.0 \\
\hline
\end{tabular}

Table 3. Antimalarial drugs used in the treatment of uncomplicated malaria.

\begin{tabular}{lcc}
\hline Variables & Frequency & Percentage \\
\hline Tab artemether/lumefantrine & 1,564 & 64.6 \\
Tab sulfadoxine + pyrimethamine & 119 & 4.9 \\
IM artemether + artemether/lumefantrine & 320 & 13.2 \\
Dihydroartemisinin + piperaquine phosphate & 72 & 3.0 \\
IM artesunate + artemether/lumefantrine & 65 & 2.7 \\
IM artemether + artemether/lumefantrine+ tab & 5 & 0.2 \\
quinine & & \\
Tab sulfadoxine/pyrimethamine + artemether/ & 62 & 2.6 \\
lumefantrine & & \\
IM artemether & 14 & 0.6 \\
IM artemether + sulfadoxine/pyrimethamine & 94 & 3.9 \\
Tab quinine & 2 & 0.1 \\
Tab quinine + artemether/lumefantrine & 1 & 0.1 \\
IM artemether + proguanil + artemether/ & 44 & 1.8 \\
lumefantrine & & \\
Sulfadoxine/pyrimethamine + proguanil & 15 & 0.6 \\
IV artesunate + sulfadoxine/pyrimethamine & 23 & 1.0 \\
IV artesunate + artemether/lumefantrine & 20 & 0.8 \\
Total & 2,420 & 100 \\
\hline
\end{tabular}

\section{DISCUSSION}

The study audited malaria cases of 2,420 patients. From the socio-demographic data obtained, the majority of the patients were females with a female-to-male ratio of $2: 1$. A high 
Table 4. Total cost of treatment in Naira for uncomplicated malaria.

\begin{tabular}{lcccc}
\hline Variable & Mean \pm SD & Minimum & Maximum & Sum \\
\hline Antimalarial drug cost & $748.87 \pm 336.75$ & 150.00 & $2,800.00$ & $1,804,020.00$ \\
Other drug costs & $267.23 \pm 154.85$ & 108.00 & $1,400.00$ & $646,708.00$ \\
Laboratory fee & $108.29 \pm 240.12$ & 0.00 & 700.00 & $262,050.00$ \\
Registration fee & $440.08 \pm 233.25$ & 100.00 & 600.00 & $1,065,000.00$ \\
Consultation fee & $476.12 \pm 326.56$ & 0.00 & 700.00 & $1,152,200.00$ \\
Admission Fee & $188.51 \pm 488.39$ & 0.00 & 2,400 & $456,200.00$ \\
Total cost of treatment & $2,234.07 \pm 1,307.59$ & 430.00 & $6,524.00$ & $5,381,886.00$ \\
\hline
\end{tabular}

Table 5. The correlation between the total cost of treatment and the number of days hospitalized.

\begin{tabular}{llcc}
\hline & \multicolumn{3}{c}{ Correlations } \\
\hline & & Total cost of treatment & Number of days hospitalized \\
\hline \multirow{2}{*}{ Total cost of treatment } & Pearson's correlation & 1 & $0.356^{\mathrm{a}}$ \\
& Sig. (two-tailed) & & 0.000 \\
& $N$ & 2409 & 365 \\
& Pearson's correlation & $0.356^{\mathrm{a}}$ & 1 \\
Number of days & Sig. (two-tailed) & 0.000 & 365 \\
hospitalized & $N$ & 365 & \\
& & &
\end{tabular}

${ }^{a}$ Correlation is significant at the 0.01 level (two-tailed).

female proportion of patients diagnosed with malaria were also observed in a previous study (Obieche and Odili, 2016), where the prevalence was $65.5 \%$. Since malaria is not gender based, it could be inferred that females visited the hospital more due to uncomplicated malaria. It could also be as a result of having antenatal clinics in the two health facilities studied. The majority of the patients who were hospitalized spent at least 2 days. This value is less than that observed in another study in which the mean number of days lost to illness was three 3 days for an adult suffering from malaria infection (Musa et al., 2013).

In this study, presumptive malaria treatment was evident and comparable with the observation from a study by Obieche and Odili (2016) to evaluate malaria treatment cost in adults in Benin City, Nigeria. This presumptive treatment may have resulted in overdiagnosis of malaria as well as overtreatment. Previous studies have also reported overdiagnosis and overtreatment (Ndyomugyenyi et al., 2007; Oladosu and Oyibo, 2013). Possible effects of this practice are the high wastage of limited resources on antimalarial medications. An issue that can be linked to low malaria laboratory investigation is noncompliance or unwillingness to pay by the patients. All the expenses were paid by the patients, thus supporting the statement that "a high facility cost of treatment contributes to higher household expenditures" (Usman and Adebayo, 2011). In Nigeria, about $50 \%$ of the citizens live below the poverty line of US $\$ 1.90$ (The World Bank, 2015) and more than $70 \%$ of healthcare expenditures are borne by individuals and households (World Health Organization, 2014). This is occasioned by the low percentage of enrollment into any of the existing forms of the health insurance scheme (Monye, 2006). About $50 \%$ of the patients from our study were self-employed; most likely, the majority of them paid OOP for their treatment.
This makes it almost impossible for the sick person to pay for healthcare services including medical investigation. Ethiopia also experiences a high economic burden due to malaria. About 55\% of the direct cost of malaria borne by the household were medical costs, namely, antimalarial/other medications cost, malaria testing costs, and consultation costs (Tefera et al., 2020).

Since the objective of this study was to estimate the direct medical treatment cost of uncomplicated malaria, we used the cost of illness method of measurement. The mean total direct cost of treatment of uncomplicated malaria was slightly lower than the finding by Obieche and Odili (2016) who obtained a mean total cost of 3,110.50 NGN . Also, it was slightly higher than a Nigerian study that obtained a total of 1,112 NGN per month using the WTP-- approach (Jimoh et al., 2007). The cost of medications used in the malaria-related symptoms accounted for $45.5 \%$ of the total expenditure. The total treatment cost for each year increases as the year progresses with the highest cost in the year 2017, while the year 2018 had the lowest cost. This is due to the fact that the data obtained were just for 6 months in 2018. It can be speculated from this study that, despite malaria control interventions' scaleup, which included free supply of ACTs for all ages, malaria continues to economically burden low-income earners of countries like Nigeria, where the national minimum wage as at the period of study was 18,000.00 NGN (\$107.14).

A study conducted in rural communities in Nigeria by Onwujekwe et al. (2000) showed that malaria treatment cost incurred by households was $49.9 \%$ of curative healthcare costs which were aggregated to a mean malaria expenditure of $\$ 1.84$ by each household monthly. Furthermore, a later study (Musa et al., 2013) showed that African families spend US \$2-25 on malaria treatment and US \$15-20 on preventive measures monthly. 
Similarly, in the study of Sicuri et al. (2011), the healthcare system costs per case of pediatric malaria treatment in Tanzania, Kenya, and Ghana were US \$2.8-123 (439.6$19,311)$, US $\$ 1.75-48$, and US $\$ 2.77-57$, respectively . Earlier in 2007, Ethiopia recorded US $\$ 2.76$ and US $\$ 1.44$ as the mean treatment costs per patient at private clinics and public facilities, respectively. However, the estimated mean direct cost of malaria incurred by each patient was US $\$ 1.60$ (Deressa et al., 2007). In a study in Kenya among children in district hospitals being treated for mild and severe malaria, the estimated providers' treatment cost was US $\$ 47-$ US $\$ 75$ per patient (Ayieko et al., 2009).

On average, ACTs cost about 20 times more than the previously used medications like sulfadoxine-pyrimethamine and chloroquine. Because of this high cost, people with lower socioeconomic status have been predicted to adhere poorly to ACTs (Yakasai et al., 2015).

Medical bills from malaria treatments can negatively impact people with limited economic means. In other words, such bills can be catastrophic (Worrall et al., 2005).

This study showed a positive significant correlation coefficient between the length of hospital stay and total treatment cost. A recent study by Sabermahani et al. (2020) demonstrated that a longer hospital stay negatively impacts both direct medical and nonmedical costs. In other words, reducing the number of days hospitalized for a patient will definitively reduce OOP-expenditures (Sabermahani et al., 2020).

\section{LIMITATION OF THE STUDY}

One limitation was the fact that the study was carried out in only one state in the country. Since the state is not representative of the whole country, caution should be taken in generalizing the results obtained from the study. Therefore, further studies need to be carried out in other parts of the country as well. Secondly, the study was retrospective thereby making it impossible to ascertain the absence of treatment failure in the cases surveyed. Treatment failure has an additive effect on the direct medical cost of malaria treatment. A longitudinal and prospective study would address this.

\section{CONCLUSION AND RECOMMENDATION}

The average direct medical cost for uncomplicated malaria treatment was 2,234.07 NGN (\$6.2) and the average amount spent directly on drug costs was 748.87 NGN (\$2.08). These amounts differed in both hospitals but were high considering the minimum earning of a government-employed Nigerian; thus, the direct cost of treating malaria was high contributing to a significant economic burden even after the adoption of ACTs in Nigeria.

As Nigeria set a target of achieving malaria preelimination and a reduction to nil of the number of malaria-related deaths by 2020 (Federal Ministry of HealthMOH, 2015), there is a need to ensure that the cost of procurement of the recommended antimalarial combination as well as the cost of diagnosis (RDT and microscopy) is affordable to the poorest of the poor. Otherwise, they go for cheaper traditional medicines which have no demonstrated benefits against the Plasmodium species. This will increase the incidence of treatment failures, thereby delaying the pre-elimination of the disease from the general populace.

\section{AUTHOR CONTRIBUTIONS}

All authors made substantial contributions to conception and design, acquisition of data, or analysis and interpretation of data; took part in drafting the article or revising it critically for important intellectual content; agreed to submit to the current journal; gave final approval of the version to be published; and agree to be accountable for all aspects of the work. All the authors are eligible to be an author as per the international committee of medical journal editors (ICMJE) requirements/guidelines.

\section{FUNDING}

There is no funding to report.

\section{CONFLICTS OF INTEREST}

The authors report no financial or any other conflicts of interest in this work.

\section{ETHICAL APPROVALS}

Ethical approval for the study was obtained from the Ethics Review Board, University of Nigeria Teaching Hospital, Ituku-Ozalla Enugu State, with the number NHREC/05/01/2008BFWA00002458-IRB00002323. Approval was also obtained from the management of Bishop Shanahan Hospital and Nsukka District Hospital.

\section{PUBLISHER'S NOTE}

This journal remains neutral with regard to jurisdictional claims in published institutional affiliation.

\section{REFERENCES}

Ahuru R, Omon IJ. The economic burden of malaria: evidence from Nigeria's data. Amity J Healthc Manage, 2018; 3(1):28-39.

Ayieko P, Akumu AO, Griffiths UK, English M. The economic burden of inpatient paediatric care in Kenya: Household and provider costs for treatment of pneumonia, malaria and meningitis. Cost Effective Resour Allocation, 2009; 7(3):1-13; doi:10.1186/1478-7547-7-3

Babamale OA, Ugbomoiko US. Status of malaria infection in peri-urban community of North Central region of Nigeria. J Bacteriol Parasitol, 2016; 07(01):1-6; doi:10.4172/2155-9597.1000256

Dalaba MA, Akweongo P, Aborigo R, Awine T, Azongo DK, Asaana P, Atuguba F, Oduro A. Does the national health insurance scheme in Ghana reduce household cost of treating malaria in the Kassena-Nankana districts. Glob Health Action, 2014; 7(1):1-7; doi:10.3402/gha.v7.23848

Deressa W, Hailemariam D, Ali A. Economic costs of epidemic malaria to households in rural Ethiopia. Trop Med Int Health, 2007; 12(10):1148-56; https://doi.org/10.1111/j.1365-3156.2007.01901.x

Ezenduka CC, Falleiros DR, Godman BB. Evaluating the treatment costs for uncomplicated malaria at a public healthcare facility in Nigeria and the implications. Pharmacoecon Open, 2017; 1(3):185-194; doi:10.1007/s41669-017-0021-8

Falade CO, Ogundele AO, Yusuf BO, Ademowo OG, Ladipo SM. High efficacy of two artemisinin-based combinations (artemether lumefantrine and artesunate plus amodiaquine) for acute uncomplicated malaria in Ibadan, Nigeria. Trop Med Int Health, 2008; 13(5):635-43; doi:10.1111/j.1365-3156.2008.02043.x

Federal Ministry of Health. Federal Republic of Nigeria national antimalarial treatment Federal Ministry of Health. Federal Ministry of Health, Vienna, Austria, 2005.

Federal Ministry of Health. National Malaria Strategic Plan 2014 - 2020. Federal Ministry of Health, Vienna, Austria, 2015.

Jimoh A, Sofola O, Petu A, Okorosobo T. Quantifying the economic burden of malaria in Nigeria using the willingness to pay approach. Cost Effective Resour Allocation, 2007; 5(6):1-8; doi:10.1186/1478-7547-5-6 
Maiyaki M, Garbati M. The burden of non-communicable diseases in Nigeria; in the context of globalization. Ann Afr Med, 2014; 13(1):1-10; doi:10.4103/1596-3519.126933

Monye FN. An appraisal of the national health insurance scheme of Nigeria. Commonw Law Bull, 2006; 32(3):415-27; doi:10.1080/03050710601074450

Musa O, Nurudeen S, Sanni A. Malaria burden and the effectiveness of malaria control measures in Nigeria: a case study of asa local government area of Kwara State. J Econ Sustain Dev, 2013; 4(3):295-308.

National Bureau of Statistics. Federal Republic of Nigeria 2006 population census. Official Gazette, 500. National Bureau of Statistics, Beijing, China, 2006.

Ndyomugyenyi R, Magnussen P, Clarke S. Diagnosis and treatment of malaria in peripheral health facilities in. Malar J, 2007; 6(36):1-8; doi:10.1186/1475-2875-6-39

Obieche OA, Odili VU. Evaluation of cost of treatment of malaria in adults in Benin City, Nigeria: patients' perspective. MalariaWorld J, 2016; 7(12):12. Available via Www.Malariaworld.Org

Okoli CO, Ugwu EC, Ubaka CM, Ezike AC, Akah PA. Efficacy of artesunate-amodiaquine combination therapy for uncomplicated malaria in patients in South-Eastern Nigeria. J Appl Res, 2010; 10(1):17-23.

Okorosobo T, Okorosobo F, Mwabu G, Orem NJ, Kirigia MJ. Economic burden of malaria in six countries of Africa. Eur J Bus Manag, $2011 ; 3(6): 42-63$

Oladosu OO, Oyibo WA. Overdiagnosis and overtreatment of malaria in children that presented with fever in Lagos, Nigeria. Infect Dis, 2013; 2013:1-7; doi:10.5402/2013/914675

Onwujekwe O, Chima R, Okonkwo P. Economic burden of malaria illness on households versus that of all other illness episodes: a study in five malaria holo-endemic Nigerian communities. Health Policy, 2000; 54(2):143-59; doi:10.1016/S0168-8510(00)00105-6

Sabermahani A, Sirizi MJ, Zolala F, Ms SN. Out-of-Pocket Costs and Importance of Nonmedical and Indirect Costs of Inpatients. Value Health Reg Issues, 2020; 24:141-7; doi:10.1016/j.vhri.2020.05.004

Sicuri E, Vieta A, Lindner L, Sauboin C. Economic costs of malaria in children in three sub-saharancountries: Ghana, Tanzania and Kenya. Trop Med Int Health, 2011; 16(Suppl. 1):117.

Tefera DR, Sinkie SO, Daka DW. Economic burden of malaria and associated factors among rural households in Chewaka district, Western Ethiopia. Clinicoecon Outcomes Res, 2020; 12:141-52; doi:10.2147/ CEOR.S241590
The World Bank. World development indicators | DataBank. DataBank, Dallas, TX, 2015. Available via http://databank.worldbank.org/ data/

Udezi WA, Usifoh CO, Ihimekpen OO. Willingness to pay for three hypothetical malaria vaccines in Nigeria. Clin Ther, 2010; 32(8):153344; doi:10.1016/j.clinthera.2010.07.018

Usman A, Adebayo MO. Socio-Economic impact of Malaria Epidemics On Households in Nigeria: Micro evidence from Kwara State Int J Asian Soc Sci, 2011; 1(5):188-96.

World Health Organization. Global health expenditure database. World Health Organization, Geneva, Switzerland, 2014. Available via http://apps.who.int/nha/database/StandardReport.aspx?ID=REP_WEB_ MINI TEMPLATE WEB VERSION\&COUNTRYKEY $=84011$

World Health Organization. World malaria report 2019. World Health Organization, Geneva, Switzerland, 2019.

Worrall E, Basu S, Hanson K. Is malaria a disease of poverty? A review of the literature. Trop Med Int Health, 2005; 10(10):1047-59; doi:10.1111/j.1365-3156.2005.01476.x

Xia S, Ma JX, Wang DQ, Li SZ, Rollinson D, Zhou SS, Zhou $\mathrm{XN}$. Economic cost analysis of malaria case management at the household level during the malaria elimination phase in The People's Republic of China. Infect Dis Poverty, 2016; 5(1):1-8; doi:10.1186/s40249-016-0141-x

Yakasai AM, Hamza M, Dalhat MM, Bello M, Gadanya MA, Yaqub ZM, Ibrahim DA, Hassan-Hanga F. Adherence to artemisininbased combination therapy for the treatment of uncomplicated malaria: a systematic review and meta-analysis. J Trop Med, 2015; 2015; doi: $10.1155 / 2015 / 189232$

How to cite this article:

Ayogu EE, Mosanya AU, Onuh JC, Adibe MO, Ubaka CM, Ukwe CV. Direct medical cost of treatment of uncomplicated malaria after the adoption of artemisinin-based combination therapy in Nigeria. J Appl Pharm Sci, 2021; 11(09):029-034. 